\title{
Adipokines in obesity and metabolic diseases
}

\author{
Marco Giammanco, ${ }^{1}$ Herbert R. Marini, ${ }^{2}$ Socrate Pallio, ${ }^{2}$ Manfredi Marco Giammanco, ${ }^{3}$ \\ Giovanni Tomasello, ${ }^{4}$ Francesco Carini, ${ }^{4}$ Fabio Venturella, ${ }^{5}$ Gaetano Leto, ${ }^{6}$ Maurizio La Guardia ${ }^{5}$ \\ ${ }^{1}$ Department of Surgical, Oncological and Oral Sciences, University of Palermo; ${ }^{2}$ Department of Clinical and \\ Experimental Medicine, University of Messina; ${ }^{3}$ Department Department of Human Pathology in Adulthood and \\ Childhood "G. Barresi", Medical School University of Messina; ${ }^{4}$ Departments of Biomedicine, Neuroscience and \\ Advanced Diagnostics; ${ }^{5}$ Department of Biological Chemical and Pharmaceutical Sciences and Technologies; \\ 6Department of Maternal and Child Health Promotion of Internal Medicine, University of Palermo, Italy
}

\begin{abstract}
Adipose tissue secretes many adipokines that regulate important physiological functions. Growing studies have highlighted that these bioactive molecules may contribute to the development of metabolic and cardiovascular diseases. Adipokines exert systemic metabolic effects and independent activity on numerous cells of the cardiovascular system, including cardiomyocytes and vascular cell walls. Adiponectin shows anti-inflammatory and anti-atherosclerotic activity on blood vessels. Conversely, resistin is endowed with pro-inflammatory effects and stimulates the proliferation of smooth muscle cells, thus promoting the development of atherosclerotic plaque. Leptin plays an important role in cardiac remodeling and blood pressure regulation through the activation of the sympathetic system. Obesity is a pathological condition associated with hypertrophy of white adipose tissue, which stimulates the production of pro-inflammatory adipokines while, it reduces the production of anti-inflammatory adipokines. The delicate balance among the production of pro-and anti-inflammatory molecules generated by adipose tissue affects, not only the development of metabolic complications associated with obesity, but also the onset and progression of atherosclerosis. Therefore,
\end{abstract}

Correspondence: Marco Giammanco, Department of Surgical,

Oncological and Oral Sciences, University of Palermo, Italy.

E-mail:marco.giammanco@unipa.it

Key words: Adipokines; adipose tissue; metabolic syndrome; obesity; cardiovascular disease.

Conflict of interest: The authors declare no potential conflict of interest.

Received for publication: 23 February 2020.

Accepted for publication: 6 March 2020.

${ }^{\circ}$ Copyright: the Author(s), 2020

Licensee PAGEPress, Italy

Journal of Biological Research 2020; 93:8915

doi:10.4081/jbr.2020.8915

This article is distributed under the terms of the Creative Commons Attribution Noncommercial License (by-nc 4.0) which permits any noncommercial use, distribution, and reproduction in any medium, provided the original author(s) and source are credited. adipokines may be regarded as potential agents of clinical interest in the treatment of a wide range of metabolic disorders and as potential biomarkers useful for early detection of metabolic, cardiovascular and inflammatory diseases.

\section{Introduction}

Adipose Tissue (AT) is a an organ whose cellular composition varies according to age, gender and tissue distribution. ${ }^{1}$ For many decades it has been considered as a passive organ that functioned, under conditions of excess energy intake, only as lipid storage depot, to provide energy-rich substrates needed by other tissues. ${ }^{2}$ Actually, AT it is recognized as a metabolically active organ, having endocrine and secretory functions, which synthesizes and secretes bioactive molecules such as adipocytokines. ${ }^{3-5}$ These molecules contribute to regulate various physiological functions such as food intake, insulin sensitivity and inflammatory processes. ${ }^{6}$ In mammals there are two different types of AT, e.g. white and brown tissue, which have different morphology and function. In humans, Brown Adipose Tissue (BAT) is present in infants and is less represented in adults. Brown adipocytes are smaller than white adipocytes. The main function of BAT consists in heat production (thermogenesis), through the oxidization of fatty acids present inside the adipocyte. ${ }^{3,4,7}$ BAT takes the name by its colour, due to the presence of intense vascularization and the wide content of mitochondria. ${ }^{8,9}$ On the other hand, White Adipose Tissue (WAT) is widely distributed throughout the body. It is mainly present in the dermis and in the subcutaneous region of the hollow organs and abdominal and mediastinal cavities. WAT has the function of mechanical cushion, reduction of trauma and allows the sliding of muscles filaments maintaining their integrity. ${ }^{3,7}$ Furthermore, WAT acts as a thermal insulator. ${ }^{4}$ It accumulates triglycerides, thus providing energy in the form of fatty acids. ${ }^{9}$ WAT represents the largest endocrine organ in humans. It has been shown to secrete numerous hormones, growth factors, enzymes, cytokines, complement factors and matrix proteins involved in the regulation of different physiological processes, including food intake, energy consumption, metabolic homeostasis, immunity and blood pressure. ${ }^{10,11}$ AT induce its effects through endocrine, paracrine and autocrine signals. ${ }^{1,12}$ The endocrine functions of WAT were first hypothesized following the early observations showing that it influenced steroids conversion, and later in 1994 following the identification of leptin., ${ }^{4,7}$ 


\section{Metabolic syndrome}

The metabolic syndrome represents a clinical condition characterized by obesity, insulin resistance (decreased ability of the tissues to respond to the action of insulin) and hypertension. It is often associated with dyslipidaemias and Non-Alcoholic Fatty Liver Disease (NAFLD) and represents a risk factor for type 2 diabetes mellitus and cardiovascular disease. ${ }^{13,14}$

Obesity, especially abdominal obesity, which is considered a chronic inflammatory disease, has been shown to play a key role (Figure 1). The inflammatory condition associated with the metabolic syndrome is characterized by the presence high concentrations of pro-inflammatory molecules, such as C-reactive protein, TNF- $\alpha$, Resistin, IL-6, IL-8, visfatin and adiponectin. ${ }^{15}$ Low levels of adiponectins has been observed in both adults and children with metabolic syndrome. On the contrary, higher levels of adiponectins have been shown to exert a protective function against the onset of metabolic syndrome. ${ }^{16}$

\section{Insulin resistance and adipokines}

AT is a tissue that responds to the action of insulin which, in turn, stimulates the accumulation of triglycerides in the AT through various mechanisms. ${ }^{17}$ Insulin resistance induced by obesity is related to an increased secretion of cytokines and bioactive substances by the AT, and to an increase in macrophages infiltrating the AT which account for a chronic inflammatory state. ${ }^{13,18-20}$ These proteins are secreted by adipocytes and cells of the immune system, and in particular by macrophages. Many of these molecules such as Monocyte Chemoattractant Protein (MCP-1), Tumor Necrosis Factor- $\alpha$ (TNF- $\alpha$ ), interleukin-6 (IL-6), IL-18, leptin, resistin, Plasminogen Activator Inhibitor (PAI-1), visfatin, Retinol-

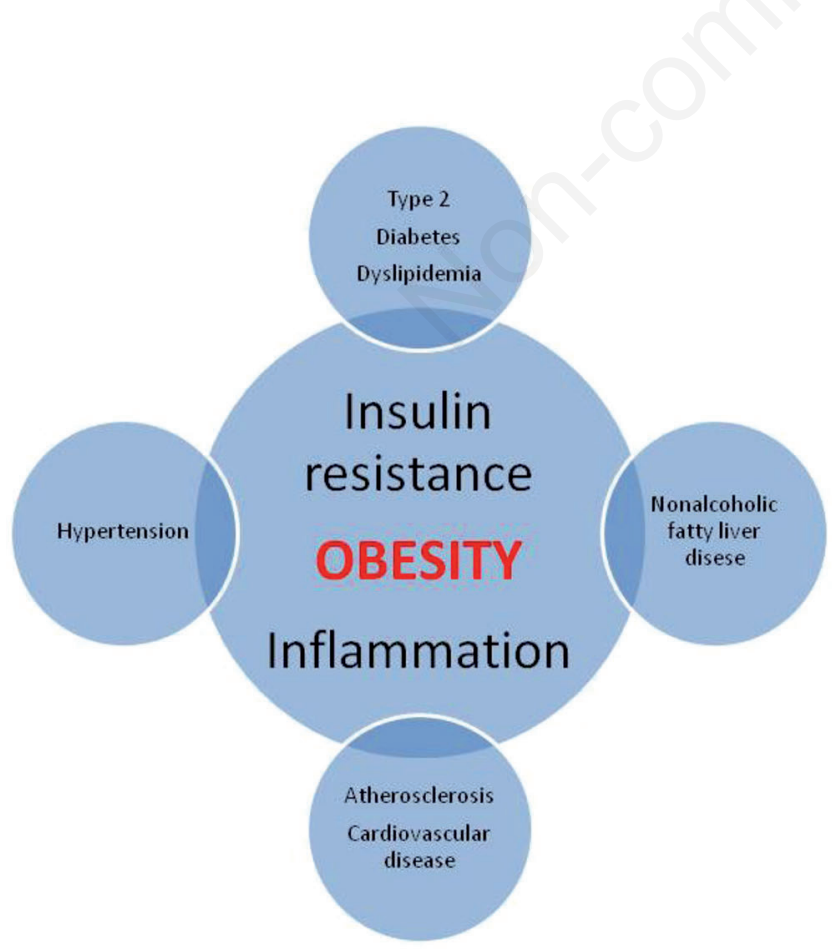

Figure 1. Obesity as a proinflammatory and pathogenic factor.
Binding Protein-4 (RBP-4) have pro-inflammatory activity, while others such as adiponectin, Secreted Frizzled-Related Protein-5 (SFRP-5) are anti-inflammatory adipokines. ${ }^{21} \mathrm{TNF}-\alpha$ is a proinflammatory cytokine which can contribute to the pathogenesis of obesity and insulin resistance. ${ }^{22}$ In humans, the expression of TNF$\alpha$ is increased in obesity and in presence of insulin resistance. However, the correlation between TNF- $\alpha$ plasma levels and insulin resistance is relatively weak. ${ }^{22,23}$ IL- 6 is a cytokine associated with the development of insulin resistance in obesity. ${ }^{24}$ In humans, 10$35 \%$ of the circulating levels of IL- 6 are produced by adipose tissue, and its production increased following hypertrophic enlargement of adipocytes. ${ }^{25}$ On the other hand, in vitro and in vivo studies have shown that IL-6 expression levels are positively associated with insulin. ${ }^{26}$ However, the correlation between IL-6 and obesity or insulin resistance remains controversial. IL-18 is another proinflammatory cytokine produced by AT. ${ }^{27}$ Circulating levels of IL18 are increased in obese subjects and decrease following weight loss. ${ }^{28}$ However, further studies are needed to confirm the role of IL-6 and IL-18.

\section{Leptin}

The discovery of leptin as a product of the $o b$ gene in obese mice dates to $1994 .{ }^{29}$ Leptin is a protein secreted primarily from AT. Its plasma levels are increased in subjects with a higher fat mass. Leptin secretion increases after a meal, due to the increase in insulin secretion. Leptin is secreted, at lower concentrations, from placenta, gastric epithelium, bronchial mucosa and mammary gland. Glucocorticoids, acute infections and pro-inflammatory cytokines contribute to increasing leptin levels, while exposure to cold, adrenergic stimulation, Growth Hormone (GH), thyroid hormones, melatonin, cigarette smoking and thiazolidinediones reduce its circulating levels. ${ }^{11,30-33}$ Circulating leptin is higher in women than in men, as a result of inhibition by androgens and stimulation by estrogens. This hormone plays an important role in regulating food intake, energy consumption and fertility. In the hypothalamus, leptin increases the synthesis of the anorexic peptides $\alpha-\mathrm{MSH}$ and decreases the synthesis of orexic peptide (NPY), with a consequent reduction of the appetite. ${ }^{34}$ In obese subjects, the circulating levels of the hormone are increased due to the onset of leptin resistance. ${ }^{35}$ Furthermore, leptin receptors are expressed in the central reward processing pathway, These findings suggest that the reduction of food intake induced by leptin is not only related to its effect on hypothalamus. ${ }^{36,37}$ Leptin reduces insulin secretion and its metabolic effects ${ }^{38-41}$ while it increases fat oxidation. ${ }^{42}$ Leptin promotes also apoptosis of adipocytes ${ }^{43-46}$ and is endowed with pro-inflammatory effects. Consistent with these findings, leptin has been observed to promote the production of pro-inflammatory cytokines (IL-2 and IFN- $\gamma)^{47}$ and contributes to maintaining a chronic state of inflammation in obese patients. ${ }^{48}$

\section{Resistin}

Resistin is an adipokine secreted by adipocytes that promotes both inflammation and insulin resistance in mouse models. ${ }^{49}$ Data on the correlation between resistin and metabolic disorders in humans are still controversial. In fact, although, some studies have reported a close relationship between resistin levels and obesity, insulin resistance or type 2 diabetes, other studies have highlighted no association between resistin and insulin resistance. ${ }^{50,51}$ The circulating levels of resistin are increased in both experimental obese animals and humans, while they are reduced by rosiglitazone administration. ${ }^{52,53}$ 


\section{Visfatin}

Nicotinamide Phosphoribosyltransferase (NAMPT), also known as visfatin was initially described as an adipokine secreted mainly by visceral adipose tissue. ${ }^{54}$ Subsequent studies in humans have shown that visfatin is also expressed in other tissues. However, its insulin-mimetic role appears controversial. ${ }^{55,56}$

\section{Adiponectin}

Adiponectin is an adipokine specifically secreted by adipose tissue. ${ }^{57}$ There are three circulating isoforms of adiponectine, e.g. trimer, hexamer and multimeric complex. ${ }^{58}$ Two adiponectin receptors have recently been identified. AdipoR1 is a receptor for globular adiponectin and is abundantly expressed in skeletal muscle, whereas AdipoR2, a receptor for full-length adiponectin, is mainly expressed in the liver. Two types of adiponectin receptors contain seven transmembrane domains have been identified, namely AdipoR1 which is expressed in skeletal muscle and AdipoR2 which is expressed in skeletal muscle and liver. The expression of these receptor results decreased in obesity-related insulin resistance. ${ }^{59} \mathrm{~A}$ member of the cadherin super family, T-cadherin, has been identified as a potent receptor for the hexameric form and for an adiponectin oligomer. ${ }^{60}$ Adiponectin induces an increase in insulin sensitivity. This molecule exerts anti-inflammatory and anti-apoptotic functions on various types of cells, and acts at hypothalamic level as regulator of energy homeostasis. In particular it increases energy consumption thus causing weight loss. ${ }^{61}$ The circulating levels of adiponectin are decreased in presence of metabolic disorders. ${ }^{61}$ On the other hand, adiponectin expression is reduced in adipose tissue, in obese subjects and in insulin resistant subjects compared to lean subjects. Furthermore, this phenomenon is associated with a reduced insulin sensitivity and a low expression of TNF- $\alpha$ in the adipose tissue. ${ }^{62}$ The restoration of proper adiponectin levels could be of clinical relevance as a new therapeutic approach in the treatment of metabolic disorders associated with obesity. ${ }^{63}$ In this context, synthetic orally active agonists of adiponectin receptors that bind and activate AdipoR1 and AdipoR2 receptors, i.e., the so called AdipoRon, have been challenged on diabetics and obese mice. The results obtained were like those observed with adiponectin (i.e., increase in sensitivity and tolerance to glucose, reduction of cardiovascular pathologies and cancer). In addition, these studies also showed an significant increase in the life span of mice. However, further studies are needed to better define the pharmacological and toxicological profile of these molecule and their long-term effects. ${ }^{64}$

\section{Frizzled-related secreted protein- 5}

Secreted Frizzled-Related Protein-5 (SFRP-5) is a protein endowed with insulin sensitizing and anti-inflammatory properties. It is highly expressed in the AT and exert beneficial effects on metabolic dysfunctions. ${ }^{65}$ The results from emerging studies have highlighted a positive correlation between SFRP-5 levels and carbohydrate parameters in healthy and obese subjects. However, further investigation is needed to better assess this phenomenon. ${ }^{66}$

\section{Apelin}

Apelin is an adipokine involved in the regulation of glucose homeostasis. ${ }^{67}$ The circulating levels of Apelin are increased in obese patients and in patients with insulin resistance and liver cirrhosis. ${ }^{67,68}$ Conversely, decreased serum levels of Apelin hare associated with an improved insulin sensitivity, a phenomenon which does not appear to be associated with a significant weight loss. ${ }^{68}$ Experimental in vivo studies in mice, indicate a possible correlation of Apelin with glucose homeostasis, obesity and related diseases. However further studies are needed in humans to better define these effects.

\section{Vaspin}

Vaspin is a novel serine protease inhibitor (serpin), with insulin-sensitizing effect, produced by visceral adipose tissue. It is also expressed in the hypothalamus, stomach, and pancreatic islets of rodents. ${ }^{69}$ The underlying mechanisms which may account for the improving effect of Vaspin on glucose metabolism remain to be fully unravelled. ${ }^{70}$

\section{Nesfatin-1}

Nesfatin-1 is an adipokine expressed in central nervous system, pituitary gland, stomach, pancreas, testes, and in the adipose tissue. This new molecule appears to be involved in the regulation of food intake by acting through a leptin-independent mechanism. ${ }^{71}$ Experimental observations in mice have shown that Nesphatin-1 is implicated in adaptive responses to stress conditions and has glucose-dependent insulinotropic effects. ${ }^{72,73}$ However, studies on humans on the effective physiological role of this neuro-peptide are still lacking.

\section{Dipeptidyl-dipeptidase-4}

Dipeptidyl-Dipeptidase-4 (DPP-4) is an adipokine secreted by AT. ${ }^{74}$ DPP-4 circulating levels correlate with the size of adipocytes and with the inflammatory conditions of the AT. ${ }^{7,75}$ DPP- 4 is present in the circulation in overweight and obese subjects ${ }^{76}$ and may be responsible of the onset of insulin resistance in adipocytes and skeletal muscle. It is likely that the metabolic effects of DPP-4 could, at least in part, be related to its function. In fact, this adipokine is implicated in the degradation of GLP-1, an incretin that reduces peripheral resistance to insulin. This hypothesis is supported by the observations that the circulating levels of DPP-4 in insulin-sensitive obese patients are lower compared to those determined in insulin-resistant obese patients. ${ }^{75}$ Therefore, the increased levels of DPP-4 may contribute to obesity and insulin resistance. The increased activity and concentration of DPP-4 in obese subjects may be useful as possible a therapeutic target in the treatment of obesity and related diseases.

\section{Interleukin-1 $\beta$}

Interleukin-1 $\beta$ (IL-1 $\beta$ ) is a pro-inflammatory cytokine expressed and secreted by AT. ${ }^{77}$ This cytokine is involved in inflammatory processes responsible of pancreatic beta cells destruction occurring in type diabetes $1 .{ }^{78}$

\section{Adipokines and obesity and diabetes related diseases}

\section{Hypertension}

Adiponectin levels are lower in patients with arterial hypertension than in normotensive patients. Therefore, the increased levels of this molecule appear to correlate with a reduced of the risk of hypertension. Adiponectin is an important biological modulator of vascular remodeling related to obesity and vascular disorders. This molecule regulates blood pressure through mechanisms mediated by the nervous system and endothelium. ${ }^{79,80}$ In vitro studies have shown that it reduces the proliferation of smooth muscle cells and inhibits the expression and the biological effects of TNF- $\alpha$ in macrophages, thus reducing their molecular adhesion and transfor- 
mation into foamy cells. ${ }^{81}$ The anti-atherogenic properties of adiponectin are mainly due to the production of Nitric Oxide (NO) in endothelial cells ${ }^{79,80}$ which induces relaxation of blood vessels relaxation and exerts anti- inflammatory and antithrombotic effects on the blood vessel walls. ${ }^{82}$

\section{Chronic kidney disease}

Chronic kidney pathologies and the related functional and structural changes of this organ caused by glomerulomegaly, glomerulosclerosis, diabetic nephropathy, renal carcinoma, nephrolithiasis, are related to obesity. Although endothelial dysfunctions are recognized as the pathogenetic mechanism of chronic kidney diseases, some adipokines such as leptin, proinflammatory cytokines and adiponectin can also contribute to kidney disfunctions. In addition, weight loss and decreased apodiponectin levels may hinder the progression of kidney damage ${ }^{83,84}$ However, the mechanisms responsible for the increased adiponectin levels observed in presence of kidney damage and the clinical significance of this phenomenon remain controversial. Further investigation are needed to better clarify these mechanisms. ${ }^{85}$ Visfatin/nampt is also implicated in chronic renal pathologies. In particular, visfatin/nampt levels have been shown to be positively associated with some circulating markers of endothelial dysfunction including Vascular Cell Adhesion Protein-1 (VCAM-1), Intracellular Adhesion Protein -1 (ICAM- 1), Melanoma Cell Adhesion Molecule-1 (MCAM-1). ${ }^{86,87}$ Conversely visfatin/nampt levels were inversely associated with the rate endothelial function expressed as brachial artery flow-mediated dilation or as rate of glomerular filtration rate..$^{88,89}$

\section{Diabetic retinopathy}

Diabetic retinopathy is one of the most frequent microvascular complications, affecting $30-50 \%$ of diabetic patients. ${ }^{90}$ Adiponectin levels were decreased in obese subjects and type 2 diabetes patients. In the latter case the levels of circulating adiponectin resulted lower in presence of diabetic retinopathy as compared to patients without retinopathy. ${ }^{91}$ Furthermore, a positive correlation was observed between low plasma levels of adiponectin and severity of diabetic retinopathy. ${ }^{92}$ In patients with proliferative diabetic retinopathy, Vascular Endothelial Growth Factor (VEGF) and adiponectin levels were significantly more elevated in the aqueous humor than in the control group. ${ }^{93,94}$ This phenomenon could be due to either an increased permeability of the blood-retinal barrier or to the local reparative process of endothelial dysfunction. Adiponectin induces endothelial production of $\mathrm{NO}$ in vitro. ${ }^{95}$ The administration of the angiogenesis inhibitor bevacizumab, may significantly reduce VEGF and adiponectin levels.

\section{Dyslipidemia}

The term dyslipidemia refers to an abnormal increase in lipids (cholesterol and triglycerides) in the blood. Dyslipidemia is often associated with obesity and is a well known risk factor for cardiovascular disease. Obesity related dyslipidemia is mainly characterized by increased plasma levels of Free Fatty Acids (FFA) and Triglycerides (TG), decreased levels of High Density Lipoproteins (HDL) and an abnormal Low Density Lipoproteins (LDL) composition. ${ }^{21}$ An increased release of FFAs by adipose tissue can result a increased FFAs uptake from the liver. This effect, in turn, determines an enhanced release of TG from the liver associated with an increased production of Very-Low-Density Lipoproteins (VLDL), and inhibition of Lipoprotein-Lipase (LPL) in adipose tissue and skeletal muscle. These effects, in turn, give rise to hypertriglyc- eridemia. In addition, the increase of VLDL from liver can inhibit lipolysis of chylomicrons, thus contributing to the increase of plasma TGs. TGs of VLDL are exchanged with Cholesterol Esters (CE) from LDL and HDL from Cholesteryl Ester Transfer Protein (CETP), producing TG rich LDL and HDL. LDL and HDL of TGs are then hydrolyzed by the liver lipase, producing small and dense LDL and HDL. The decrease in HDL concentrations and the synthesis of small and dense LDL have been associated with an increase in cardiovascular risk. ${ }^{21}$ On the other hand, a correlation between dyslipidemia and amount of visceral adipose tissue has been observed in patients with type 2 diabetes. ${ }^{96}$ The onset of dyslipidemia is also influenced by inflammatory molecules released by adipose tissue, such as TNF- $\alpha$, IL-6, IL-1, Amyloid Serum A (SAA) and adiponectins. In obese patients, the presence of infiltrating macrophages in adipose tissue is positively correlated with circulating TG levels, while it is inversely correlated with plasma HDL cholesterol levels. ${ }^{97}$ Circulating TNF- $\alpha$ levels are increased in hyperlypidemic patients and correlate positively with VLDL concentrations. ${ }^{98}$ TNF- $\alpha$ and IL-6 levels are increased in subjects with hypertriglyceridemia. ${ }^{99,100} \mathrm{TG}$ plasma levels remain elevated in the presence of increased levels of anti-inflammatory cytokines, such as IL-10. ${ }^{101}$ In healthy subjects and in subjects with cardiovascular diseases, proinflammatory cytokines, such as TNF- $\alpha$, IL6 and IL-1, promote the increase in circulating levels of total cholesterol and LDL-cholesterol, by activating the cholesterol synthesis. These cytokines result also negatively associated with serum cholesterol-HDL levels. ${ }^{102-104}$ However, a positive correlation was found between the concentrations of the anti-inflammatory cytokine IL-10 and HDL cholesterol plasma levels while, a negative correlation between IL-10 levels and high levels of total cholesterol and LDL cholesterol was noted. ${ }^{101}$ Adiponectin has beneficial effects on lipid metabolism ${ }^{105}$ and insulin sensitivity, as it stimulates fatty acids oxidation and the use of glucose through the activation of AMPK in the liver and muscle skeletal. ${ }^{106}$ Furthermore, plasma adiponectin levels negatively correlated with TG levels while they positively correlated with HDL cholesterol levels. ${ }^{107}$ On the other hand, decreased levels of adiponectin have been shown to be associated with dyslipidaemias and cardiovascular disease. ${ }^{108,109}$ Recent studies have suggested the decrease of adiponectin levels in the blood as a useful marker for dyslipidaemias in subjects with polycystic ovary syndrome being at increased risk of dyslipidemia. ${ }^{110}$

\section{Non alcoholic liver steatosis}

Non-alcoholic liver steatosis (Non-Alcoholic Liver Disease, NAFLD) is the most common form of chronic liver inflammation and it is related to obesity. ${ }^{111-113}$ The development of NAFLD is characterized by two phases: the first phase is characterized by hepatic steatosis (accumulation of TG in the liver), followed in the second phase, which is associated with inflammation and fibrosis (Non-Alcoholic Steatohepatitis, NASH). ${ }^{13}$ The development of NAFLD and its progression to NASH are explained by the "two hits" hypothesis. According to this hypothesis, the "first hit" foster the accumulation of lipids in the liver, while the "second hit", causes hepatocytes damage, inflammation and fibrosis, ${ }^{113}$ as a consequence of the release of proinflammatory cytokines, adipokines, mitochondrial dysfunctions, oxidative stress and lipid peroxidation. The "two hits" hypothesis has been renamed "multi-hits" hypothesis. This following the discovery of the contribute of various factors in the development of NAFLD, such as lipid dysfunction, imbalance of adipokines, inflammation in the AT, oxidative stress and insulin resistance. ${ }^{114,115}$ In the "multi-hit" hypothesis, the imbalance between lipid metabolism and insulin resistance is considered as 
"first-hit". Insulin resistance induced by hyperinsulinemia, causes liver steatosis by increasing de novo liver lipogenesis, FFA efflux from the AT due to increased lipolysis, by decreasing liver oxidation and reducing VLDL secretion. Following the onset of steatosis, the liver becomes more vulnerable to "multi-hit" factors, including bacterial toxins derived from the intestine, cytokine/adipokine imbalance, mitochondrial dysfunction, oxidative damage, unbalanced apoptosis in hepatocytes, release of pro-fibrogenic factors and inflammatory mediators from damaged organelles and activation of Kupffer cells. These factors contribute to stimulating inflammation, apoptosis, fibrosis, which lead to liver diseases progression. ${ }^{116,117}$ In obese patients, the pro-inflammatory and antiinflammatory factors secreted by the AT are associated with NAFLD. ${ }^{118}$ In particular, it has been suggested that adiponectin possess anti-inflammatory activity, which may protect from hepatic steatosis and inflammation, and that, in the liver, it increases the suppressive activity of insulin on glucose production. ${ }^{119}$ The circulating levels of adiponectin are lower in subjects with NAFLD than in healthy subjects ${ }^{120}$ and are inversely correlated with biomarkers of normal liver function in healthy subjects. ${ }^{121}$ On the other hand a low level of adiponectin is a marker of liver steatosis and increase the levels of enzymes characterizing liver damage in obese subjects. ${ }^{122}$ Furthermore, in patients with NASH there is a reduction in the expression of adiponectin and its associated receptor AdipoR 2 compared to patients with steatosis alone. ${ }^{123}$

Leptin is also involved in NAFLD, as it directly stimulates AMPK, which is involved in the activation of lipid oxidation ( $\beta$ oxidation and glycolysis) and in the inhibition of lipogenesis. ${ }^{124}$ There is a negative correlation between serum leptin levels and liver damage in humans ${ }^{125}$ and a positive correlation between serum leptin levels and elevated serum ALT levels or hepatic steatosis. These effects has been shown to be independent from body mass index or body fat mass index. ${ }^{126,127}$ Furthermore, in animal models while leptin increases in the presence of liver fibrosis, a decrease in its levels is correlated with a reduction in liver damage. ${ }^{128}$ Moreover, leptin is a powerful mitogen and an inhibitor of apoptosis of Kupffer cells. ${ }^{129}$

Studies carried out in experimental animals have highlighted that resistin regulates glucose and lipid metabolism and that may act as a mediator insulin resistance in the liver. Increased resistin values are found in NAFLD patients ${ }^{130,131}$ and in NASH patients compared to patients with pure steatosis. However, in humans, the role of resistin is still not well known. Therefore, further study are needed to unravel its functions TNF- $\alpha$ is involved in the early and late stages of NAFLD in both in animals and humans. In particular this cytokine appear to modulate the transition from NASH to NAFLD. ${ }^{132-134}$

\section{Adipokines and cardiovascular diseases}

Cardiovascular Diseases (CVDs) are the largest cause of death in the world. They are characterized by alteration of myocardial contractility, inflammation, and vascular damage. These pathological conditions include, hypertension, atherosclerosis, endothelial and myocardial cell dysfunctions. Risk factors for CVDs are hypertension, cigarette smoking, type 2 diabetes, overweight, hyperlipidemia, metabolic syndrome, and family history lifestyle (unhealthy diet and lack of exercise). ${ }^{135}$ Adipokines also play an important role in the pathogenesis of CVDs. ${ }^{136}$

\section{Adiponectin}

In the heart, adiponectin mediates its action through the presence of three receptors e.g., AdipoR1, AdipoR2 and T-cad- herin. ${ }^{60,137-139}$ Adiponectin receptors are also expressed in platelets, where they mediate the inhibiting effects of adiponectin on collagen-induced aggregation. ${ }^{140}$ Adiponectin has anti-atherogenic properties, as it suppresses cell adhesion to the vascular endothelium and promotes angiogenesis. ${ }^{105}$ This peptide is also endowed with anti-inflammatory properties, due to its ability in suppressing NF-kB factor, thus hindering the development of atherosclerosis. Adiponectin can also inhibit the conversion of macrophages into foamy cells and decreases LDL. ${ }^{81}$ Adiponectin can also play a role in cardiac remodeling, which consists in thwarting $i$ the extent of myocardial hypertrophy. ${ }^{141}$ In humans, the plasma levels of adiponectin are inversely correlated with insulin resistance and the severity of coronary artery disease. ${ }^{142}$ On the other hand, no correlations between serum adiponectin levels and risk of coronary heart disease have been reported. However, it has been suggested that the lack of correlation might be probably due to the different adiponectin oligomers tested. ${ }^{143}$ However, increased adiponectin levels are correlated with a reduction in the risk of myocardial infarction in humans ${ }^{144}$ and with a lower risk of coronary heart disease in diabetic patients. ${ }^{145}$ However, unlike it may be expected, the circulating levels of this protein decreased after a myocardial infarction. ${ }^{146}$ These findings indicate that adiponectin has a beneficial role in cardiovascular pathologies and atherosclerosis.

\section{Leptin}

Leptin is is not exclusively produced by adipocytes but also by cardiomyocytes and Smooth Muscle Vascular Cells (VSMC). ${ }^{147,148}$ Leptin and its receptors have been detected in cardiomyocytes, ${ }^{149}$ in VSMC, ${ }^{150}$ in endothelial cells, ${ }^{151}$ in the myometrium ${ }^{152}$ and in cerebral and coronary vessels. ${ }^{153,154}$ Humans hyperleptinemia is associated with atherosclerosis, hypertension and metabolic syndrome. In particular, this hormone has been shown to play an important role in the early stages of atherosclerosis development, and, in particular, during the recruitment of leukocytes and macrophages in the endothelial wall. ${ }^{155}$ In humans, increased serum leptin levels are associated with an increased risk of myocardial infarction and stroke, which is independent from obesity and cardiovascular risk factors. ${ }^{156}$ These effects have been, in part, explained with the ability of leptin to increase insulin resistance, to alter hemostasis balance and to induce vascular inflammation. ${ }^{157}$ Besides its proinflammatory properties, leptin possesses pro-atherogenic properties. In fact this molecule has been reported to promote i) production of proliferative and profibrinotic cytokines, ii) to induces oxidative stress through Reactive Oxygen Species (ROS) generation, ${ }^{158}$ iii) to stimulate cardiomyocyte hypertrophy ${ }^{159}$ and VSMCs proliferation, iv) to stimulate platelet aggregation and $\mathrm{v}$ ) to increase the expression of pro-atherogenic lipoprotein lipase. ${ }^{160}$ On the other hand, there are conflicting results on the role of leptin in CVDs. While some of these studies find a positive association between leptin concentration and hypertension, ${ }^{161}$ other studies have highlighted a significant vasodilator effect induced by leptin in coronary heart disease. ${ }^{162}$ Leptin contributes to the development of obesity-related hypertension by increasing the secretion of pro-inflammatory cytokines such as TNF- $\alpha$ and IL-6, and by generating ROS in endothelial cells. ${ }^{155,158}$ Increased leptin levels have been reported to be also associated with hypertension. Various mechanisms such as activation of the renin-angiotensin system, hyperactivity of the sympathetic nervous system, endothelial dysfunction and reduction of the effect of renal pressure on elimination may be involved in this phenomenon. ${ }^{163}$ The heart itself produces leptin, which can act locally to induce its physiological effects. ${ }^{164,165}$ Leptin has a nega- 
tive inotropic effect mediated by $\mathrm{NO}^{166}$ and regulates cardiac contractility, ${ }^{167}$ size of cardiomyocytes and production extracellular matrix components. ${ }^{168}$ Leptin has been also indicated to have beneficial effects, such as reduction of lipid toxicity on the heart, ${ }^{169}$ protection of cardiomyocytes from the hypoxia-induced damages ${ }^{170}$ and myocardial remodelling. ${ }^{171}$ The protective effects of leptin from damages induced by ischemia is further supported by the "obesity paradox", i.e., the unexpected reduction of co-morbidity and mortality associated with cardiovascular diseases in subjects with high body mass index. ${ }^{165}$

\section{Resistin}

Elevated plasma levels of resistin are correlated with proatherogenic inflammatory markers, ${ }^{172}$ increased cardiovascular risk, unstable angina, adverse prognosis of coronary diseases and metabolic syndrome. ${ }^{173,174}$ Resistin has a pro-inflammatory role in atherosclerosis, as it induces the expression of VCAM-1 and Intercellular Adhesion Molecule-1 (ICAM-1), ${ }^{175}$ increases the expression of proinflammatory cytokines (IL-1, IL-6, IL-12, TNF$\alpha) ;{ }^{176,177}$ and the release of endothelin-1. In line with these observations, studies on atherosclerosis carried out in experimental animal models, have shown that resistin levels correlated with the severity of the sclerotic lesion. ${ }^{178}$ In addition, the action of resistin is inhibited by adiponectin. ${ }^{175}$

\section{Visfatin}

Visfatin is mainly produced and secreted in visceral fat. However, it is also present in perivascular and epicardial adipose tissue. ${ }^{179,180}$ Visfatin expression is positively associated with lipid metabolism and atherosclerosis. ${ }^{181}$ In particular, it has been shown that this molecule plays a role in the destabilization of atherosclerotic plaques ${ }^{182}$ and inflammation. Consistent with these observations high levels of visfatin have been reported to induce the expression of VCAM-1 and ICAM-1, and to increase the expression of pro-inflammatory cytokines. ${ }^{183}$ On the other hand, plasma visfatin levels result inversely correlated with vascular endothelial functions. ${ }^{184}$ However, visfatin has been reported to exert beneficial effects. For instance, this hormone stimulates endothelial proliferation and capillary formation in human endothelial cells, ${ }^{185}$ reduces apoptosis in human VSMCs. ${ }^{186}$ Furthermore, experimental studies have shown that in rats, it reduces cardiac contractility and induces vasodilatation mediated by NO produced by the endothelium. ${ }^{187}$ In an in vivo ischemia-reperfusion models, a single i.v. push of visfatin has been shown to reduce the size of the infarcted area by $50 \%$ and to protect from the damage due to reoxygenation of the cardiomyocytes. ${ }^{188-190}$ In patients with coronary artery disease and acute myocardial infarction, visfatin levels are positively associated with unstable atherosclerotic lesions. Furthermore, visfatin promotes destabilization of plaques and their rupture in different types of acute coronary syndromes. ${ }^{182}$ This molecule appears to play also a role in both atherosclerosis and endothelial dysfunctions. ${ }^{191}$ In vitro studies and in vivo studies suggest that visfatin may have a neuroprotective role towards cerebral venous thrombosis ischemia. ${ }^{192}$ Overall, visfatin can help to exacerbate angiogenesis caused by ischemic heart disease, diabetes or atherosclerosis, and could, therefore, be considered a new target for more effective treatments of these pathological conditions. ${ }^{191}$

\section{Apelin}

Apelin is a peptide produced and secreted by adipocytes, vascular stroma and cardiovascular tissues. ${ }^{193}$ Apelin is expressed in endothelial cells of the endocardium while, its receptor APJ is expressed in cardiomyocytes. This suggest that the apelin system acts on the heart by increasing cardiac contractility and heart rate. ${ }^{194-196}$ Plasma apelin levels are positively associated with body mass index and obesity, which is considered one of the major causes of CVDs. ${ }^{197}$ On the other hand, decreased apelin levels are observed in patients with atrial fibrillation not associated with other CVDs ${ }^{198}$ and chronic heart damage. ${ }^{199}$ Overall, apelin is currently considered an adiponectin with a favorable effect for CVDs, as it reduces atherogenesis, macrophage activity, cardiomyocyte contractility, atrial fibrillation and heart damage. However, further studies are needed to clearly outline its role in different myocardial pathologies. ${ }^{136}$

\section{Omentin}

Omentin is an adipocytokine that is abundantly expressed in the adipocytes present in the vascular stroma. It has anti-inflammatory, anti-atherogenic and anti-diabetic properties. ${ }^{200}$ Omentin plays an important role in the pathogenesis of vascular coronary diseases, mainly in coronary artery atherosclerosis. ${ }^{201}$ Studies undertaken in mice have shown that omentin promotes cellular endothelial functions and revascularization in response to ischemia. ${ }^{202}$ Serum omentin levels are lower in patients with acute coronary syndrome or with stable angina pectoris than in healthy subjects. ${ }^{203}$ Omentine could be a potential biomarker to predict the development and progression of coronary heart disease in patients with metabolic syndrome. ${ }^{204}$

\section{Chemerin}

Chemerine is a relatively recent adipokine. Its cardiovascular properties have still not well established. Chemerin plasma levels are positively correlated with the metabolic syndrome and associated risk factors, such as body mass index, hypertension and hypertriglycaeridemia ${ }^{205}$ Chemerin levels are increased in patients with severe obesity. ${ }^{206}$ This adipokine appears to reduce inflammation in endothelial cells by inducing NO synthesis which, in turn, inhibits VCAM-1 mediated TNF- $\alpha$ induction and the consequent lymphocyte adhesion through the suppression of the activation of the NF-kB factor and that of the p38 signaling pathway. ${ }^{207}$ It also promotes endothelial angiogenesis and the production and activity of matrix metalloproteinase ${ }^{208}$ while reduces adhesion to endothelial walls ${ }^{207}$ and enhances the contractile response to phenylepinephrine in VSCMs and in the endothelium. ${ }^{209}$

\section{Adipokines and gestational diabetes mellitus}

Gestational Diabetes Mellitus (GDM), is a frequent complication of pregnancy that can cause considerable risks to the mother and the fetus. ${ }^{210}$ Untreated GDM, can progress to type 2 diabetes. $^{211}$ GDM occurs in 3-7\% of pregnancies ${ }^{212}$ and mostly in the second trimester of pregnancy, due to the increased insulin resistance and decreased function of pancreatic beta cells. ${ }^{213}$ Normally, $\beta$-cells adapt to insulin demands for a given physiological context. ${ }^{214}$ Following proliferative stimuli mediated by Placental Lactogen Hormone (HPL), prolactin and growth hormone, these cells increases up to $50 \%$ during pregnancy. ${ }^{215}$ During pregnancy, selected insulin requirements in women are due to insulin resistance, which is related to HPL production, food intake, body weight intake, and to the fetal presence itself. ${ }^{216,217}$ GDM increases the risk of developing type 2 diabetes and/or that of other complications in pregnancy, such as pre-eclampsia. These conditions may increase the possibility to resort to cesarean section and complications in problems, such as macrosomia. Children born from mothers with GDM have an increased risk to develop obesity and type 
2 diabetes mellitus as adults, as well as hypoglycemia, hypocalcaemia, polycythemia, jaundice and respiratory distress syndromes. ${ }^{213}$ Serum adiponectin levels progressively decrease during pregnancy. ${ }^{218,219}$ In women with GDM, the increased secretion of inflammatory cytokine could reduce the secretion of adiponectin, whose excessive low levels contribute to insulin resistance. Adiponectin may be considered a factor related to insulin resistance and pancreatic beta cell dysfunction in the pathogenesis of type 2 diabetes. ${ }^{214-216,220}$ Leptin is also secreted by the placenta. It regulates the secretion of Gonadotropin Releasing Hormone $(\mathrm{GnRH})$ and activates the orthosympathetic nervous system. In normal pregnancy, leptin concentrations are 2-3 times higher than in non-pregnant subjects and peaks around the $28^{\text {th }}$ week of gestation. Leptin has a potential role in embryo implantation, in the induction of the secretion of human chorionic gonadotropin, in the formation of trophoblastic cells and in the regulation of placenta growth. Furthermore, Leptin increases mitosis and promotes the absorption of amino acids. ${ }^{220}$ The expression of leptin in the placenta is increased in pregnant women with GDM, compared to women with a normal pregnancy. ${ }^{220}$ This could be explained with the presence of hyperinsulinemia in GDM. ${ }^{220,221}$

\section{Discussion and conclusions}

Adipokines are currently considered an exciting new link between obesity and insulin resistance, obesity and cardiovascular disease and hypertension and hyperlipidemia. Although the influence of adipokine on obesity in pathological conditions associated with obesity and metabolism has been well established, this phenomenon have been investigated more in detail. This review analyses and discuss the current findings of these studies. In general, adipokines can increase or decrease insulin sensitivity and can influence appetite and food intake. ${ }^{6}$ The increased knowledge from studies on physiological and pathological functions of new adipokines suggests that adiponectin, visfatin, vaspin and omentin may also improve the effects of insulin. ${ }^{55,56,200}$ Various studies have contributed to greatly increase our knowledge about the physiological functions of adiponectin. These studies have shown that elevated plasma levels of adiponectin are associated with a lower incidence of type 2 diabetes mellitus and that reduced expression levels of this this protein can be observed in insulin resistance. ${ }^{16}$ Unfortunately, the clinical studies undertaken so far, has failed to highlight a direct sensitizing effect of adiponectin on endogenous insulin. However, preclinical in vivo studies have suggested that adiponectin, adiponectin receptor agonists and AMPK activators may be good candidates for developing new therapeutic options for the clinical management of type 2 diabetes and obese patients. ${ }^{64}$ Furthermore, drugs that increase the expression of anti-inflammatory adiponectin in fats are also of potential interest. Other compounds including combined PPAR/PPAR-agonist could also mediate some of their effects on insulin sensitivity through similar mechanisms. On the other hand, the role of Visfatin, Vaspin and Omentin in human insulin resistance and obesity needs to be better clarified to define their therapeutic potential. Regarding the adipokine induce insulin resistance, the role of IL-6 in human insulin sensitivity and obesity is the best understood. ${ }^{24,25}$ IL- 6 increases glucose tolerance in vivo. Moreover, elevated baseline IL-6 levels are associated with an increased risk of developing a reduced glucose tolerance. ${ }^{26}$ However, therapeutic approaches based on direct inhibition of IL-6 should not probably be feasible in the clinical practice, due to various expected side effects. TNF $\alpha$ and resistin appear as the main links between insulin resistance and obesity in rodents. However, their role in humans remain still uncertain. ${ }^{15}$ In addition, clinical observations haves shown that the inhibition of TNF $\alpha$ has no effect on insulin sensitivity. Clinical studies on the physiological role PAI-1, SPARC/osteonectin, MCP-1 and RBP-4 are scanty so their role in insulin resistance and obesity, is still not well delineated. Leptin is the main appetite suppressant hormone. This adipokine is very effective in human leptin deficiency. However, the knowledge of mechanisms mediating leptin resistance in obesity it is of pivotal importance to find new therapeutic options to replenish central and peripheral leptin signaling. The results from numerous experimental and clinical studies reported in this review, highlight that various adipokines can be regarded as potential targets in the treatment of insulin resistance and obesity and related metabolic pathologies. It is now well established that the altered expression and secretion of adipokines, which occurs in obesity, especially in the visceral obesity, determines important circulatory and metabolic alterations. However, among the numerous signaling molecules and their associated effects identified by these investigations, those with potential clinical interest that might undergo to pharmacological modulation have to be still identified. Ultimately, advances in the knowledge of adipocyte biology may lead to a better understanding of the physiological functions attributed to the adipose tissue which, now is currently considered multi-functional organ rather than simply a passive storage site for excess energy.

\section{References}

1. Trzeciak-Ryczek A, Tokarz-Deptula B, NiedzwiedzkaRystwej P, Deptula W. Adipose tissue component of the immune system. Centr Eur J Immunol 2011;36:95-9.

2. Ottaviani E, Malagoli D, Franceschi C. The evolution of the adipose tissue: anel neglected enigma. Gen Comp Endocrinol 2011;174:1-4.

3. Bernlohr DA, Jenkins AE, Bennaars AA. Adipose tissue and lipid metabolism. In: Vence JE, Vence D, editors. Biochemistry of lipids, lipoproteins and membranes. 4th ed. Elsevier Science: Amsterdam; 2002. pp. 263-89.

4. Saely C, Geiger K, Drexel H. Brown versus white adipose tissue: a mini-review. Gerontol 2012;58:120-2.

5. Fasshauer M, Blüher M. Adipokines in health and disease. Trends Pharmacol Sci 2015;36:461-70.

6. Coelho M, Oliveira T, Fernandes R. Biochemistry of adipose tissue: an endocrine organ. Arch Med Sci 2013;9:191-200.

7. Fonseca-Alaniz MH, Takada J, Alonso-Vale MIC, Lima FB. Adipose tissue as an endocrine organ: from theory to practice. J Pediatr 2007;83:S192-203.

8. Fonseca-Alaniz MH, Takada J, Alonso-Vale MI, Lima FB. The adipose tissue as a regulatory center of the metabolism. Arq Bras Endocrinol Metabol 2006;50:216-29.

9. Kiess W, Petzold S, Topfer M, et al. Adipocytes and adipose tissue. Best Pract Res Clin Endocrinol Metab 2008;22:135-53.

10. Costa JV, Duarte JS. Adipose tissue and adipokines. Acta Med Port 2006;19:251-6.

11. Matsuzawa Y. The metabolic syndrome and adipocytokines. FEBS Letters 2006;580:2917-21.

12. Giammanco M, Lantieri L, Leto G, et al. Nutrition, obesity and hormones. J Biol Res 2018;91:108-18.

13. Xu H, Barnes GT, Yang Q, et al. Chronic inflammation in fat plays a crucial role in the development of obesity-related insulin resistance. J Clin Investig 2003;112:1821-30. 
14. Lumeng $\mathrm{CN}$, Saltier AR. Inflammatory links between obesity and metabolic disease. J Clin Investig 2011;121:2111-7.

15. Cnop M, Havel PJ, Utzschneider KM, et al. Relationship of adiponectin to body fat distribution, insulin sensitivity and plasma lipoproteins: evidence for independent roles of age and sex. Diabetologia 2003;46:459-69.

16. Kim NH, Cho NH, Yun $\mathrm{CH}$, et al. Association of obstructive sleep apnea and glucose metabolism in subjects with or without obesity. Diabetes Care 2013;36:3909-15.

17. Kahn BB, Flier JS. Obesity and insulin resistance. J Clin Investig 2000;106:473-81.

18. Weisberg SP, McCann D, Desai M, et al. Obesity is associated with macrophage accumulation in adipose tissue. J Clin Investig 2003;112:1796-808.

19. Fain JN. Release of inflammatory mediators by human adipose tissue is enhanced in obesity and primarily by the nonfat cells: A review. Mediators Inflamm 2010;2010:513948.

20. Ouchi N, Parcher JL, Lugus JJ, Walsh K. Adipokines in inflammation and metabolic disease. Nat Rev Immunol 2011;11:85-97.

21. Jung UJ, Choi MS. Obesity and its metabolic complications: the role of adipokines and the relationship between obesity, inflammation, insulin resistance, dyslipidemia and nonalcoholic fatty liver disease. Int J Mol Sci 2014;15:6184-6223.

22. Hotamisligil GS, Shargill NS, Spiegelman BM Adipose expression of tumor necrosis factor- $\alpha$ : Direct role in obesitylinked insulin resistance. Sci 1993;259:87-91.

23. Miyazaki Y, Pipek R, Mandarino LJ, Defronzo RA. Tumor necrosis factor $\alpha$ and insulin resistance in obese type 2 diabetic patients. Int J Obes Relat Metab Disord 2003;27:88-94.

24. Fernandez Real JM, Ricart W. Insulin resistance and chronic cardiovascular inflammatory syndrome. Endocr Rev 2003;24:278-301.

25. Sopasakis VR, Sandqvist M, Guatafson B, et al. High local concentrations and effects on differentiation implicate interleukin-6 as a paracrine regulator. Obes Res 2004;12: 454-60.

26. Bastard JP, Maachi M, Van Nhieu JT, et al. Adipose tissue IL6 content correlates with resistance to insulin activation of glucose uptake both in vivo and in vitro. J Clin Endocrinol Metab 2002;87:2084-9.

27. Wood IS, Wang B, Jenkins JR, Trayhurn P. The pro-inflammatory cytokine IL-18 is expressed in human adipose tissue and strongly upregulated by TNF alpha in human adipocytes. Biochem Biophys Res Commun 2005;337:422-9.

28. Esposito K, Pontillo A, Ciotola M, et al. Weight loss reduces interleukin-18 levels in obese women. J Clin Endocrinol Metab 2002;87:3864-6.

29. Zhang Y, Proenca R, Maffei M, et al. Positional cloning of the mouse obese gene and its human homologue. Nature 1994;372:425-32.

30. Kersten S. Mechanisms of nutritional and hormonal regulation of lipogenesis. EMBO reports 2001;2:282-6.

31. Bruno A, Siena L, Gerbino S, et al. Apigenin affects leptin/leptin receptor pathway and induces cell apoptosis in lung adenocarcinoma cell line. Eur J Cancer 2011;47:2042-51.

32. Bruno A, Gerbino S, Ferraro M, et al. Fluticasone furoate maintains epithelial homeostasis via leptin/leptin receptor pathway in nasal cells. Mol Cell Biochem 2014 Nov;396:55-65.

33. Bruno A, Giammanco M, Gjomarkaj M, Pace E. The adipokine leptin: A pleiotropic molecule in the human respiratory tract. J Biol Res 2015;88:3-5.

34. Ahima RS, Flier JS. Leptin. Ann Rev Physiol 2000;62:413-37.
35. Friedman JM, Halaas JL. Leptin and the regulation of body weight in mammals. Nature 1998;395:763-70.

36. Fulton S, Woodside B, Shizgal P. Modulation of brain reward circuitry by leptin. Sci 2000;287:125-8.

37. Figlewicz DP, Evans SB, Murphy J, et al. Expression of receptors for insulin and leptin in the ventral tegmental area/substantia nigra (VTA/SN) of the rat. Brain Res 2003;964:107-15.

38. Fehmann HC, Peiser C, Bode HP, et al. Leptin: a potent inhibitor of insulin secretion. Peptides 1997;18:1267-73.

39. Ishida K, Murakami T, Mizuno A, et al. Leptin suppresses basal insulin secretion from rat pancreatic islets. Regul Pept 1997;70:179-82.

40. Muller G, Ertl J, Gerl M, Preibisch G. Leptin impairs metabolic actions of insulin in isolated rat adipocytes. J Biol Chem 1997;272:10585-93.

41. Ookuma M, Ookuma K, York DA. Effects of leptin on insulin secretion from isolated rat pancreatic islets. Diabetes 1998;47:219-23.

42. Hwa JJ, Fawzi AB, Graziano MP, et al. Leptin increases energy expenditure and selectively promotes fat metabolism in ob/ob mice. Am J Physiol 1997;272:1204-9.

43. Della Fera MA, Qian H, Baile CA. Adipocyte apoptosis in the regulation of body fat mass by leptin. Diabetes Obes Metab 2001;3:299-310.

44. Gullicksen PS, Della Fera MA, Baile CA. Leptin-induced adipose apoptosis: Implications for body weight regulation. Apoptosis 2003;8:327-35.

45. Itoh M, Suganami T, Hachiya R, Ogawa Y. Adipose tissue remodeling as homeostatic inflammation. Int $\mathrm{J}$ Inflam 2011;2011:720926.

46. Galic S, Oakhill JS, Steinberg GR. Adipose tissue as an endocrine organ. Mol Cell Endocrinol 2010;316:129-39.

47. Grunfeld C, Zhao C, Fuller J, et al. Endotoxin and cytokines induce expression of leptin, the ob gene product, in hamsters. J Clin Investig 1996;97:2152-7.

48. Paz Filho G, Mastronardi C, Franco CB, et al. Leptin: Molecular mechanisms, systemic pro-inflammatory effects, and clinical implications. Arq Bras Endocrinol Metabol 2012;56:597-607.

49. Qi Y, Nie Z, Lee YS, et al. Loss of resistin improves glucose homeostasis in leptin deficiency. Diabetes 2006;55:3083-90.

50. Kielstein JT, Becker B, Graf S, et al. Increased resistin blood levels are not associated with insulin resistance in patients with renal disease. Am J Kidney Dis 2003;42:62-6.

51. Patel L, Buckels AC, Kinghorn IJ, et al. Resistin is expressed in human macrophages and directly regulated by PPAR $\gamma$ activators. Biochem Biophys Res Commun 2003;300:472-6.

52. Steppan C, Bailey S, Bhat S, et al. The hormone resistin links obesity to diabetes. Nature 2007;409:307-12.

53. Guzik TJ, Mangalat D, Korbut R. Adipocytokines-novel link between inflammation and vascular function? J Physiol Pharmacol 2006;57:505-28.

54. Fukuhara A, Matsuda M, Nishizawa M, et al. Visfatin: a protein secreted by visceral fat that mimics the effects of insulin. Sci 2005;307:426-30.

55. Berndt J, Kloting N, Kralisch S, et al. Plasma visfatin concentrations and fat depot-specific mRNA expression in humans. Diabetes 2005;54:2911-6.

56. Revollo JR, Korner A, Mills KF, et al Nampt/PBEF/Visfatin regulates insulin secretion in beta cells as a systemic NAD biosynthetic enzyme. Cell Metabolism 2007;6:363-75.

57. Palanivel R, Fang X, Park M, et al. Globular and full-length 
forms of adiponectin mediate specific changes in glucose and fatty acid uptake and metabolism in cardiomyocytes. Cardiovasc Res 2007;75:148-57.

58. Kaser S, Tatarczyz T, Stadlmayr A, et al. Effect of obesity and insulin sensitivity on adiponectin isoform distribution. Eur $\mathbf{J}$ Clin Invest 2008;38:827-34.

59. Kadowaki T, Yamauchi T, Kubota N, et al. Adiponectin and adiponectin receptors in insulin resistance, diabetes, and the metabolic syndrome. J Clin Investig 2006;116:1784-92.

60. Hug C, Wang J, Ahmad NS, et al. T-cadherin is a receptor for hexameric and high-molecular-weight forms of Acrp30/ adiponectin. Proc Natl Acad Sci USA 2004;101: 10308-13.

61. Turer AT, Scherer PE. Adiponectin: mechanistic insights and clinical implications. Diabetologia 2012;55:2319-26.

62. Kern PA, Di Gregorio GB, Lu T, et al. Adiponectin expression from human adipose tissue: Relation to obesity, insulin resistance, and tumor necrosis factor-alpha expression. Diabetes 2003;52:1779-85.

63. Lim S, Quon MJ, Koh KK. Modulation of adiponectin as a potential therapeutic strategy. Atherosclerosis 2014;233:721-8.

64. Okada Iwabu M, Yamauchi T, Iwabu M, et al A small-molecule AdipoR agonist for type 2 diabetes and short life in obesity. Nature 2013;503:493-9.

65. Ouchi N, Higuchi A, Ohashi K, et al. Sfrp5 is an anti-inflammatory adipokine that modulates metabolic dysfunction in obesity. Sci 2010;329:454-7.

66. Carstensen M, Herder C, Kempf K, et al. Sfrp5 correlates with insulin resistance and oxidative stress. Eur J Clin Investig 2013;43:350-7.

67. Castan Laurell I, Dray C, Attane C, et al. Apelin, diabetes, and obesity. Endocrine 2011;40:1-9.

68. Krist J, Wieder K, Kloting N, et al. Effects of weight loss and exercise on apelin serum concentrations and adipose tissue expression in human obesity. Obesity Facts 2013; 6:57-69.

69. Kloting N, Kovacs P, Kern M, et al. Central vaspin administration acutely reduces food intake and has sustained blood glucose-lowering effects. Diabetologia 2011;54:1819-23.

70. Heiker JT, Kloting N, Kovacs P, et al. Vaspin inhibits kallikrein 7 by serpin mechanism. Cell Mol Life Sci 2013;70:2569-83.

71. Stengel A, Tache R. Mini review: Nesfatin-1-an emerging new player in the brain-gut, endocrine, and metabolic axis. Endocrinol 2011;152:4033-8.

72. Gonzalez R, Reingold BK, Gao X, et al. Nesfatin-1 exerts a direct, glucose-dependent insulinotropic action on mouse islet $\beta$ - and MIN6 cells. J Endocrinol 2011;208:9-16.

73. Nakata M, Manaka K, Yamamoto $S$, et al. Nesfatin-1 enhances glucose-induced insulin secretion by promoting $\mathrm{Ca} 2+$ influx through L-type channels in mouse islet $\beta$-cells. Endocr J 2011;58:305-13.

74. Lamers D, Famulla S, Wronkowitz N, et al. Dipeptidyl peptidase 4 is a novel adipokine potentially linking obesity to the metabolic syndrome. Diabetes 2011;60:1917-25.

75. Sell H, Bluher M, Kloting N, et al. Adipose dipeptidyl peptidase-4 and obesity: correlation with insulin resistance and depot-specific release from adipose tissue in vivo and in vitro. Diabetes Care 2013;36:4083-90.

76. Weyer C, Foley JE, Bogardus C, et al. Enlarged subcutaneous abdominal adipocyte size, but not obesity itself, predicts type II diabetes independent of insulin resistance. Diabetologia 2000;43:1498-506

77. Sopasakis VR, Nagaev I, Smith U. Cytokine release from adi- pose tissue of nonobese individuals. Int J Obesity 2005;29: 1144-7.

78. Larsen CM, Faulenbach M, Vaag A, et al. Interleukin-1-receptor antagonist in type 2 diabetes mellitus. N Engl J Med 2007;356:1517-26

79. Iwashima $\mathrm{Y}$, Katsuya $\mathrm{T}$, Ishikawa $\mathrm{K}$, et al. Hypoadiponectinemia is an independent risk factor for hypertension. Hypertension 2004;43:1318-23.

80. Di Chiara T, Licata A, Argano C, et al. Plasma adiponectin: a contributing factor for cardiac changes in visceral obesityassociated hypertension. Blood Pressure 2014;23:147-53.

81. Ouchi N, Kihara S, Arita Y, et al. Adipocyte-derived plasma protein, adiponectin, suppresses lipid accumulation and class A scavenger receptor expression in human monocyte-derived macrophages. Circulation 2001;103:1057-63.

82. Chen Z, Peng I, Sun W, et al. AMP-activated protein kinase functionally phosphorylates endothelial nitric oxide synthase ser633. Circulation Res 2009;104:496-505.

83. Mathew AV, Okada S, Sharma K. Obesity related kidney disease. Curr Diabs Reviews 2011;7:41-9.

84. Tesauro M, Mascali A, Franzese O, et al. Chronic kidney disease, obesity, and hypertension: the role of leptin and adiponectin. Intern J Hypertension 2012;2012.943605.

85. Komura N, Kihara S, Sonoda M, et al. Increment and impairment of adiponectin in renal failure. Cardiovasc Res 2010;86:471-7.

86. Malyszko J, Malyszko JS, Mysliwiec M. Visfatin, a new adipocytokine, is predominantly related to inflammation/ endothelialdamage in kidney allograft recipients. Transplant Proc 2009;41:150-3.

87. Malyszko J, Malyszko JS, Pawlak K, Mysliwiec M. Visfatin and apelin, new adipocytokines, and their relation to endothelial function in patients with chronic renal failure. Adv Med Sci 2008;53:32-6.

88. Yilmaz MI, Saglam M, Carrero JJ, et al. Serum visfatin concentration and endothelial dysfunction in chronic kidney disease. Nephrol Dialysis Transplant 2008;23:959-65.

89. Axelsson J, Witasp A, Carrero JJ, et al. Circulating levels of Visfatin/pre-B-cell colony-enhancing factor 1 in relation to genotype, GFR, body composition, and survival in patients with CKD. Am J Kidney Diseases 2007;49:237-44.

90. Klein BE. Overview of epidemiologic studies of diabetic retinopathy. Ophth Epidemiol 2007;14:179-83.

91. Yilmaz MI, Sonmez A, Acikel C, et al. Adiponectin may play a part in the pathogenesis of diabetic retinopathy. Eur J Endocrinol 2004;151:135-40.

92. Misu H, Ishikura K, Kurita $\mathrm{S}$, et al. Inverse correlation between serum levels of selenoprotein $\mathrm{p}$ and adiponectin in patients with type 2 diabetes. PLoS ONE 2012;7:e34952.

93. Costagliola C, Daniele A, Dell'Omo R, et al. Aqueous humor levels of vascular endothelial growth factor and adiponectin in patients with type 2 diabetes before and after intravitreal bevacizumab injection. Exper Eye Res 2013;110:50-4.

94. Mao D, Peng H, Li Q, et al. Aqueous humor and plasma adiponectin levels in proliferative diabetic retinopathy patients. Curr Eye Res 2012;37:803-8.

95. Chen H, Montagnani M, Funahashi T, et al. Adiponectin stimulates production of nitric oxide in vascular endothelial cells. J Biol Chem 2003;278:45021-26.

96. Sam S, Haffner S, Davison MH, et al. Relationship of abdominal visceral and subcutaneous adipose tissue with lipoprotein particle number and size in type 2 diabetes. Diabetes 2008;57:2022-7. 
97. Cancello R, Tordjman J, Poitou C, et al. Increased infiltration of macrophages in omental adipose tissue is associated with marked hepatic lesions in morbid human obesity. Diabetes 2006;55:1554-61.

98. Jovinge S, Hamsten A, Tornvall P, et al. Evidence for a role of tumor necrosis factor alpha in disturbances of triglyceride and glucose metabolism predisposing to coronary heart disease. Metabolism 1998;47:113-8.

99. Mohrschladt MF, Weverling Rijnsburger AW, De Man FH, et al. Hyperlipoproteinemia affects cytokine production in whole blood samples ex vivo. The influence of lipid-lowering therapy. Atherosclerosis 2000;148:413-9.

100. Jonkers IJ, Mohrschladt MF, Westendorp RG, et al. Severe hypertriglyceridemia with insulin resistance is associated with systemic inflammation (reversal with bezafibrate therapy in a randomized controlled trial). Am J Med 2002;112:275-80.

101. Van Exel E, Gussekloo J, De Craen AJ, et al. Leiden 85 Plus Study. Low production capacity of interleukin-10 associates with the metabolic syndrome and type 2 diabetes: The Leiden 85-Plus Study. Diabetes 2002;51:1088-92.

102. Fernandez Real JM, Gutierrez C, Ricart W, et al. Plasma levels of the soluble fraction of tumor necrosis factor receptors 1 and 2 are independent determinants of plasma cholesterol and LDL-cholesterol concentrations in healthy subjects. Atherosclerosis 1999;146:321-7.

103. Skoog T, Dichtl W, Boquist S, et al. Plasma tumour necrosis factor-alpha and early carotid atherosclerosis in healthy middle-aged men. Eur Heart J 2002;23:376-83.

104. Mizia Stec K, Zahorska Markiewicz B, Mandecki T, et al. Hyperlipidaemias and serum cytokines in patients with coronary artery disease. Acta Cardiol 2003;58:9-15.

105. Ouchi N, Kihara S, Arita Y, et al. Novel modulator for endothelial adhesion molecules: Adipocyte-derived plasma protein adiponectin. Circulation 1999;100:2473-6.

106. Yamauchi T, Kamon J, Minokoshi Y, et al. Adiponectin stimulates glucose utilization and fatty-acid oxidation by activating AMP-activated protein kinase. Nat Med 2002;8:1288-95.

107. Kanda H, Tateya S, Tamori Y, et al. MCP-1 contributes to macrophage infiltration into adipose tissue, insulin resistance, and hepatic steatosis in obesity. J Clin Investig 2006;116: 1494-505.

108. Matsubara M, Maruoka S, Katayose S. Decreased plasma adiponectin concentrations in women with dyslipidemia. J Clin Endocrinol Metab 2002;87:2764-9.

109. Okamoto Y, Kihara S, Funahashi T, et al. Adiponectin: A key adipocytokine in metabolic syndrome. Clin Sci 2006;110: 267-78.

110. Chang CY, Chen MJ, Yang WS, et al. Hypoadiponectinemia: A useful marker of dyslipidemia in women with polycystic ovary syndrome. Taiwan J Obstet Gynecol 2012;51:583-90.

111. Angulo P. Nonalcoholic fatty liver disease. N Engl J Med 2002;346:1221-31.

112. Lopez Velazquez JA, Silva Vidal KV, Ponciano Rodriguez G, et al. The prevalence of nonalcoholic fatty liver disease in the Americas. Ann Hepatol 2014;13:166-78.

113. Starley BQ, Calcagno CJ, Harrison SA. Nonalcoholic fatty liver disease and hepatocellular carcinoma: A weighty connection. Hepatology 2010;51:1820-32.

114. Tilg H, Moschen AR. Evolution of inflammation in nonalcoholic fatty liver disease: The multiple parallel hits hypothesis. Hepatology 2010;52:1836-46.

115. Polyzos SA, Kountouras J, Zavos C, Deretzi G. Nonalcoholic fatty liver disease: Multimodal treatment options for a patho- genetically multiple-hit disease. J Clin Gastroenterol 2012;46:272-84.

116. Bradbury MW, Berk PD. Lipid metabolism in hepatic steatosis. Clin Liver Dis 2004;8:639-71.

117. Koteish A, Diehl AM. Animal models of steatosis. Semin Liver Dis 2001;21:89-104.

118. Roden M. Mechanisms of disease: Hepatic steatosis in type 2 diabetes Pathogenesis and clinical relevance. Nat Clin Pract Endocrinol Metab 2006;2:335-48.

119. Berg AH, Combs TP, Du X, et al. The adipocyte-secreted protein Acrp30 enhances hepatic insulin action. Nat Med 2001;7:947-53.

120. Hui JM, Hodge A, Farrell GC, et al. Beyond insulin resistance in NASH: TNF-alpha or adiponectin? Hepatology 2004;40:46-54.

121. Lopez Bermejo A, Botas P, Funahashi T, et al. Adiponectin, hepatocellular dysfunction and insulin sensitivity. Clin Endocrinol 2004;60:256-63.

122. Targher G, Bertolini L, Scala L, et al. Decreased plasma adiponectin concentrations are closely associated with nonalcoholic hepatic steatosis in obese individuals. Clin Endocrinol 2004;61:700-3.

123. Kaser S, Moschen A, Cayon A, et al. Adiponectin and its receptors in non-alcoholic steatohepatitis. Gut 2005;54:117-21.

124. Minokoshi Y, Kim YB, Peroni OD, et al. Leptin stimulates fatty-acid oxidation by activating AMP-activated protein kinase. Nature 2002;415:339-43.

125. Serin E, Ozen B, Gumurdulu Y, et al. Serum leptin level can be a negative marker of hepatocyte damage in nonalcoholic fatty liver. J Gastroenterol 2003;38:471-6.

126. Poordad FF. The role of leptin in NAFLD contender or pretender? J Clin Gastroenterol 2004;38:841-3.

127. Tobe K, Ogura T, Tsukamoto C, et al. Relationship between serum leptin and fatty liver in Japanese male adolescent university students. Am J Gastroenterol 1999;94:3328-35.

128. Marra F. Leptin and liver fibrosis: A matter of fat. Gastroenterology 2002;122:1529-32.

129. Saxena NK, Titus MA, Ding X, et al. Leptin as a novel profibrogenic cytokine in hepatic stellate cells: Mitogenesis and inhibition of apoptosis mediated by extracellular regulated kinase (Erk) and Akt phosphorylation. FASEB J 2004;18:1612-4.

130. Banerjee RR, Lazar MA. Resistin: Molecular history and prognosis. J Mol Med 2003;81:218-26.

131. Pagano $C$, Soardo G, Pilon $C$, et al. Increased serum resistin in nonalcoholic fatty liver disease is related to liver disease severity and not to insulin resistance. J Clin Endocrinol Metab 2006;91:1081-6.

132. Crespo J, Cayon A, Fernandez Gil P, et al. Gene expression of tumor necrosis factor alpha and TNF-receptors, p55 and p75, in nonalcoholic steatohepatitis patients. Hepatology 2001;34:1158-63.

133. Ding WX, Yin XM. Dissection of the multiple mechanisms of TNF-alpha induced apoptosis in liver injury. J Cell Mol Med 2004;8:445-54.

134. Manco M, Marcellini M, Giannone G, Nobili V. Correlation of serum TNF-alpha levels and histologic liver injury scores in pediatric nonalcoholic fatty liver disease. Am J Clin Pathol 2007; 127:954-60.

135. Di Majo D, La Neve L, La Guardia M, et al. The influence of two different $\mathrm{pH}$ levels on the antioxidant properties of flavonols, flavan-3-ols, phenolic acids and aldehyde compounds analysed in synthetic wine and in a phosphate buffer. J Food Compos Anal 2011;24:265-9. 
136. Mattu HS, Randeva HS. Role of adipokines in cardiovascular disease. J Endocrinol 2013;216:T17-36.

137. Doyle DD, Goings GE, Upshaw-Earley J, et al. T-cadherin is a major glycophosphoinositol-anchored protein associated with noncaveolar detergent-insoluble domains of the cardiac sarcolemma. J Biol Chem 1998;273:6937-43.

138. Fujioka D, Kawabata K, Saito Y,et al. Role of adiponectin receptors in endothelin-induced cellular hypertrophy in cultured cardiomyocytes and their expression in infarcted heart. Am J Physiol Heart Circ Physiol 2006;290:2409-16.

139. Yamauchi T, Kamon J, Waki H, et al. Globular adiponectin protected ob/ob mice from diabetes and ApoE-deficient mice from atherosclerosis. J Biol Chem 2003;278:2461-8.

140. Tajmir P, Ceddia RB, Li RK, et al. Leptin increases cardiomyocyte hyperplasia via extracellular signal-regulated kinase and phosphatidylinositol 3-kinase-dependent signaling pathways. Endocrinology 2004;145:1550-5

141. Ouchi N, Shibata R, Walsh K. Cardioprotection by adiponectin. Trends Cardiovasc Med 2006;16:141-6.

142. Cesari M, Pessina AC, Zanchetta M, et al. Low plasma adiponectin is associated with coronary artery disease but not with hypertension in high-risk nondiabetic patients. J Intern Med 2006;260:474-83.

143. Sattar N, Watt P, Cherry L, et al. High molecular weight adiponectin is not associated with incident coronary heart disease in older women: a nested prospective case-control study. J Clin Endocrinol Metab 2008;93:1846-9

144. Pischot T, Girman CJ, Hotamisligil GS, et al. Plasma adiponectin levels and risk of myocardial infarction in men. JAMA 2004;291:1730-7.

145. Schulze MB, Shai I, Rimm EB, et al. Adiponectin and future coronary heart disease events among men with type 2 diabetes. Diabetes 2005;54:534-9.

146. Kojima S, Funahashi T, Sakamoto T, et al. The variation of plasma concentrations of a novel, adipocyte derived protein, adiponectin, in patients with acute myocardial infarction. Heart 2003;89:667.

147. Matsui H, Motooka M, Koike H, et al. Ischemia/reperfusion in rat heart induces leptin and leptin receptor gene expression. Life Sci 2007;80:672-80.

148. Zeidan A, Purdham DM, Rajapurohitam V, et al. Leptin induces vascular smooth muscle cell hypertrophy through angiotensin II-and endothelin-1-dependent mechanisms and mediates stretch-induced hypertrophy. J Pharmacol Exp Ther 2005;315:1075-84.

149. Rajapurohitam V, Gan XT, Kirshenbaum LA, Karmazyn M. The obesity-associated peptide leptin induces hypertrophy in neonatal rat ventricular myocytes. Circ Res 2003;93:277-9.

150. Zeidan A, Karmazyn M. Leptin and vascular smooth muscle. Curr Vasc Pharmacol 2006;4:383-93

151. Mutze J, Roth J, Gerstberger R, et al. Immunohistochemical evidence of functional leptin receptor expression in neuronal and endothelial cells of the rat brain. Neurosci Lett 2006;394:105-10.

152. Markowska A, Belloni AS, Rucinski M, et al. Leptin and leptin receptor expression in the myometrium and uterine myomas: Is leptin involved in tumor development? Int J Oncol 2005;27:1505-9.

153. Bjorbaek C, Uotani S, Da Silva B, Flier JS. Divergent signaling capacities of the long and short isoforms of the leptin receptor. J Biol Chem 1997;272:32686-95.

154. Knudson JD, Dincer UD, Zhang C, et al. Leptin receptors are expressed in coronary arteries, and hyperleptinemia causes significant coronary endothelial dysfunction. Am J Physiol Heart Circ Physiol 2005;289:H48-56.

155. Yamagishi SI, Edelstein D, Du XL, et al. Leptin induces mitochondrial superoxide production and monocyte chemoattractant protein-1 expression in aortic endothelial cells by increasing fatty acid oxidation via protein kinase A. J Biol Chem 2001;276:25096-100.

156. Sierra Johnson J, Romero Corral A, Lopez Jimenez F, et al. Relation of increased leptin concentrations to history of myocardial infarction and stroke in the United States population. Am J Cardiol 2007;100:234-9.

157. Wannamethee SG, Tchernova J, Whincup P, et al. Plasma leptin: associations with metabolic, inflammatory and haemostatic risk factors for cardiovascular disease. Atherosclerosis 2007;191:418-26.

158. Bouloumie A, Marumo T, Lafontan M, Busse R. Leptin induces oxidative stress in human endothelial cells. FASEB J 1999;13:1231-8.

159. Ghantous CM, Azrak Z, Hanache S, et al. Differential Role of Leptin and Adiponectin in Cardiovascular System. Int J Endocrinol 2015;2015:534320.

160. Beltowski J. Leptin and atherosclerosis. Atherosclerosis 2006; 189:47-60.

161. Beltowski J. Role of leptin in blood pressure regulation and arterial hypertension. J Hypertens 2006;24:789-801.

162. Momin AU, Melikian N, Shah AM, et al. Leptin is an endothelial-independent vasodilator in humans with coronary artery disease: Evidence for tissue specificity of leptin resistance. Eur Heart J 2006;27:2294-9.

163. Hall JE. The kidney, hypertension, and obesity. Hypertension 2003;41:625-33.

164. Purdham DM, Zou MX, Rajapurohitam V, Karmazyn M. Rat heart is a site of leptin production and action. Am J Physiol Heart Circ Physiol 2004;287:H2877-84.

165. Karmazyn M, Purdham DM, Rajapurohitam V, Zeidan A. Signalling mechanisms underlying the metabolic and other effects of adipokines on the heart. Cardiovasc Res 2008;79:279-86.

166. Nickola MW, Wold LE, Colligan PB, et al. Leptin attenuates cardiac contraction in rat ventricular myocytes. Role of NO. Hypertension 2000;36:501-5.

167. Dong F, Zhang X, Ren J. Leptin regulates cardiomyocyte contractile function through endothelin-1 receptor-NADPH oxidase pathway. Hypertension 2006;47:222-9.

168. Madani S, De Girolamo S, Munoz DM, Li RK, Sweeney G. Direct effects of leptin on size and extracellular matrix components of human pediatric ventricular myocytes. Cardiovasc Res 2006;69:716-25.

169. Lee Y, Naseem RH, Duplomb L, et al. Hyperleptinemia prevents lipotoxic cardiomyopathy in acyl CoA synthase transgenic mice. Proc Natl Acad Sci USA 2004;101:13624-9.

170. Erkasap N, Ikizler M, Shneyvays V, et al. Leptin protects the cardiac myocyte cultures from hypoxic damage. Life Sci 2006;78:1098-102.

171. Tardiff JC. Cardiac hypertrophy: stressing out the heart. J Clin Invest 2006;116:1467-70.

172. Kunnari A, Ukkola O, Paivansalo M, Kesaniemi YA. High plasma resistin level is associated with enhanced highly sensitive C-reactive protein and leukocytes. J Clin Endocrinol Metab 2006;91:2755-60.

173. Lubos E, Messow CM, Schnabel R, et al. Resistin, acute coronary syndrome and prognosis results from the AtheroGene study. Atherosclerosis 2007;193:121-8. 
174. Norata GD, Ongari M, Garlaschelli K, et al. Plasma resistin levels correlate with determinants of the metabolic syndrome. Eur J Endocrinol 2007;156:279-84.

175. Kawanami D, Maemura K, Takeda N, et al. Direct reciprocal effects of resistin and adiponectin on vascular endothelial cells: a new insight into adipocytokine-endothelial cell interactions. Biochem Biophys Res Commun 2004;314: 415-9.

176. Milan G, Granzotto M, Scarda A, et al. Resistin and adiponectin expression in visceral fat of obese rats: effect of weight loss. Obes Res 2002;10:1095-103.

177. Silswal N, Singh AK, Aruna B, et al. Human resistin stimulates the pro-inflammatory cytokines TNF-alpha and IL-12 in macrophages by NF-kappaB-dependent pathway. Biochem Biophys Res Commun 2005;334:1092-101.

178. Lago F, Dieguez C, Gomez Reino J, Gualillo O. The emerging role of adipokines as mediators of inflammation and immune responses. Cytokine Growth Factor Rev 2007;18:313-25.

179. Cheng KH, Chu CS, Lee KT, et al. Adipocytokines and proinflammatory mediators from abdominal and epicardial adipose tissue in patients with coronary artery disease. Int J Obes 2008;32:268-74.

180. Wang P, Xu TY, Guan YF, et al. Perivascular adipose tissuederived visfatin is a vascular smooth muscle cell growth factor: role of nicotinamide mononucleotide. Cardiovasc Res 2009;81:370-80.

181. Smith J, Al-Amri M, Sniderman A, Cianflone K. Visfatin concentration in Asian Indians is correlated with high density lipoprotein cholesterol and apolipoprotein A1. Clin Endocrinol 2006;65:667-72.

182. Dahl TB, Yndestad A, Skjelland M, et al. Increased expression of visfatin in macrophages of human unstable carotid and coronary atherosclerosis: possible role in inflammation and plaque destabilization. Circulation 2007;115:972-80.

183. Moschen AR, Kaser A, Enrich B, et al. Visfatin, an adipocytokine with proinflammatory and immunomodulating properties. J Immunol 2007;178:1748-58.

184. Takebayashi K, Suetsugu M, Wakabayashi S, et al. Association between plasma visfatin and vascular endothelial function in patients with type 2 diabetes mellitus. Metabolism 2007;56:451-8.

185. Adya R, Tan BK, Punn A, et al. Visfatin induces human endothelial VEGF and MMP-2/9 production via MAPK and PI3K/Akt signalling pathways: novel insights into visfatininduced angiogenesis. Cardiovasc Res 2008;78:356-65.

186. Van Der Veer E, Nong Z, O'Neil C, Urquhart B, et al. Pre-Bcell colony-enhancing factor regulates $\mathrm{NAD}+$-dependent protein deacetylase activity and promotes vascular smooth muscle cell maturation. Circ Res 2005;97:25-34.

187. Yamawaki H, Hara N, Okada M, Hara Y. Visfatin causes endothelium-dependent relaxation in isolated blood vessels. Biochem Biophys Res Commun 2009;383:503-8.

188. Hausenloy DJ, Yellon DM. Survival kinases in ischemic preconditioning and postconditioning. Cardiovasc Res 2006;70:240-53.

189. Hausenloy DJ, Yellon DM. Cardioprotective growth factors. Cardiovasc Res 2009;83:179-94.

190. Yellon DM, Hausenloy DJ. Myocardial reperfusion injury. N Engl J Med 2007;357:1121-35.

191. Romacho T, Sanchez Ferrer CF, Peiro C. Visfatin/Nampt: An Adipokine with Cardiovascular Impact. Mediators Inflamm 2013;2013:946427.

192. Zhang W, Xie Y, Wang T, et al. Neuronal protective role of
PBEF in a mouse model of cerebral ischemia. J Cereb Blood Flow Metab 2010;30:1962-71.

193. Lee DK, George SR, O'Dowd BF. Unravelling the roles of the apelin system: prospective therapeutic applications in heart failure and obesity. Trends Pharmacol Sci 2006;27:190-4.

194. Szokodi I, Tavi P, Foldes G, et al. Apelin, the novel endogenous ligand of the orphan receptor APJ, regulates cardiac contractility. Circ Res 2002;91:434-40.

195. Kleinz MJ, Davenport AP. Immunocytochemical localization of the endogenous vasoactive peptide apelin to human vascular and endocardial endothelial cells. Regul Pept 2004;118:119-25.

196. Kleinz MJ, Davenport AP. Emerging roles of apelin in biology and medicine. Pharmacol Ther 2005;107:198-211.

197. Heinonen MV, Purhonen AK, Miettinen P, et al. Apelin, orexin-A and leptin plasma levels in morbid obesity and effect of gastric banding. Regul Pept 2005;130:7-13.

198. Ellinor PT, Low AF, Macrae CA. Reduced apelin levels in lone atrial fibrillation. Eur Heart J 2006;27:222-6.

199. Chong KS, Gardner RS, Morton JJ, et al. Plasma concentrations of the novel peptide apelin are decreased in patients with chronic heart failure. Eur J Heart Fail 2006;8:355-60.

200. Zhou JY, Chan L, Zhou SW. Omentin: linking metabolic syndrome and cardiovascular disease. Curr Vasc Pharmacol 2014;12:136-43.

201. Ouwens DM, Sell H, Greulich S, Eckel J. The role of epicardial and perivascular adipose tissue in the pathophysiology of cardiovascular disease. J Cell Mol Med 2010;14:2223-34.

202. Maruyama S, Shibata R, Kikuchi R, et al. Fat-derived factor omentin stimulates endothelial cell function and ischemiainduced revascularization via endothelial nitric oxide synthase-dependent mechanism. J Biol Chem 2012;287: 408-17.

203. Zhong X, Zhang HY, Tan H, et al. Association of serum omentin-1 levels with coronary artery disease. Acta Pharmacol Sin 2011;32:873-8.

204. Shang FJ, Wang JP, Liu XT, et al. Serum omentin-1 levels are inversely associated with the presence and severity of coronary artery disease in patients with metabolic syndrome. Biomarkers 2011;16:657-62.

205. Bozaoglu K, Bolton K, McMillan J, et al. Chemerin is a novel adipokine associated with obesity and metabolic syndrome. Endocrinology 2007;148:4687-94.

206. Sell H, Divoux A, Poitou C, et al. Chemerin correlates with markers for fatty liver in morbidly obese patients and strongly decreases after weight loss induced by bariatric surgery. J Clin Endocrinol Metab 2010;95:2892-6.

207. Yamawaki H, Kameshima S, Usui T, et al. A novel adipocytokine, chemerin exerts anti-inflammatory roles in human vascular endothelial cells. Biochem Biophys Res Commun 2012;423:152-7.

208. Kaur J, Adya R, Tan BK, et al. Identification of chemerin receptor (ChemR23) in human endothelial cells: chemerininduced endothelial angiogenesis. Biochem Biophys Res Commun 2010;391:1762-8.

209. Lobato NS, Neves KB, Filgueira FP,et al. The adipokine chemerin augments vascular reactivity to contractile stimuli via activation of the MEK-ERK1/2 pathway. Life Sci 2012;91:600-6.

210. Soheilykhah S, Mojibian M, Rahimi Saghand S, et al. Maternal serum leptin concentration in gestational diabetes. Taiwan J Obstet Gynecol 2011;50:149-53.

211. Meller M, Qiu C, Vadachkoria S, et al. Changes in placental 
adipocytokine gene expression associated with gestational diabetes mellitus. Physiol Res 2006;55:501-12.

212. Lappas M, Yee K, Permezel M, Rice GE. Release and regulation of leptin, resistin and adiponectin from human placenta, fetal membranes, and maternal adipose tissue and skeletal muscle from normal and gestational diabetes mellitus-complicated pregnancies. J Endocrinol 2005;186:457-65.

213. Retnakaran R, Hanley AJ, Raif N, et al. Reduced adiponectin concentration in women with gestational diabetes: a potential factor in progression to type 2 diabetes. Diabetes Care 2004;27:799-800.

214. Ballesteros M, Simon I, Vendrell J, et al. Maternal and cord blood adiponectin multimeric forms in gestational diabetes mellitus: a prospective analysis. Diabetes Care 2011;34:2418-23.

215. Doruk M, Ugur M, Oruc AS, et al. Serum adiponectin in gestational diabetes and its relation to pregnancy outcome. J Obstet Gynaecol 2014;34:471-5.
216. Retnakaran R, Shen S, Hanley AJ, et al. Hyperbolic relationship between insulin secretion and sensitivity on oral glucose tolerance test. Obesity 2008;16:1901-7.

217. Cantarella CD, Ragusa D, Giammanco M, Tosi S. Folate deficiency as predisposing factor for childhood leukaemia: a review of the literature. Genes Nutr 2017;12:14.

218. Desoye G, Hauguel De Mouzon S. The human placenta in gestational diabetes mellitus. The insulin and cytokine network. Diabetes Care 2007;30:S120-6.

219. Zaretsky MV, Alexander JM, Byrd W, Bawdon RE. Transfer of inflammatory cytokines across the placenta. Obstet Gynecol 2004;103:546-50.

220. Al Badri MR, Zantout MS, Azar ST. The role of adipokines in gestational diabetes mellitus. Ther Adv Endocrinol Metab 2015;6:103-8

221. La Guardia M, Giammanco M. Breast cancer and obesity. Panminerva Med 2001;43:123-33. 